\title{
Dose Distribution in Low Energy Exposure and Measurement Accuracy with Passive Dosimeters used in Individual Radiation Protection Dosimetry
}

\author{
F. Minai*, A. Stochioiu
}

Horia Hulubei, National Institute for R\&D in Physics and Nuclear Engineering, Magurele, Ilfov

\begin{abstract}
The work proposes the study on the radiation distribution uniformity provided by a ${ }^{241} \mathrm{Am}$ standard source. The Agfa films and $\mathrm{LiF}: \mathrm{Mg}, \mathrm{Cu}, \mathrm{P}$ thermoluminescent dosimeters were irradiated at doses from $0.01 \div 10.0 \mathrm{mSv}$ range. All detectors were placed on the PMMA phantom within of the radiation solid angle. In point of $1.00 \mathrm{mSv}$ conventional dose the calculated dose was from $1.07 \mathrm{mSv}$ to $0.64 \mathrm{mSv}$ from the middle towards the edge of the solid angle. There are differences of doses into the solid ange of radiation.
\end{abstract}

DOI: 10.12693/APhysPolA.135.1081

PACS/topics: dose, measurement accuracy, dose distribution, optical density

\section{Introduction}

The dose measurement accuracy depends of the quality and limits of the detector type and the technical method used to calibrate the dosimeters, the processing and interpretation of the recorded results. The thermoluminescent and film dosimeters are the most used passive systems of radiation detection in occupationally exposure monitoring and well accepted by radiation protection norms $[1,2]$. Generally, doses measured at high energy have a good repeatability and uniform distribution in the irradiation area. In contrast to the halide film detector that contains silver with high atomic number, the thermoluminescent dosimeter response is weakly influenced by the radiation energy due to its chemical composition $\mathrm{LiF}: \mathrm{Mg}, \mathrm{Cu}, \mathrm{P}$. The film detector has a very good spatial resolution and can gives information about the incident radiation energy. Aside from the influence of energy on the dosimeter response, what can be said about the quality or distribution of the dose on the investigated surface in the case of patients or when the whole-body dose for occupationally exposure have to be assessed.

The ${ }^{241} \mathrm{Am}$ standard source is recommended in the dose assessment generated by low energy radiation [2]. In $\mathrm{x}$-ray exposure the radiation quality can generate the dose variations even within a fairly small exposed area and the dosimeter calibration to different radiation quality is recommended [3-5]. The work propose study on the uniformity distribution of the radiation provided by a ${ }^{241} \mathrm{Am}$ standard source in order to have an overview of the radiation beam quality used in dosimeter calibration and implicitly to increase the dose measurement accuracy for occupationally exposed personnel.

*corresponding author; e-mail: fmihai@nipne.ro

\section{Experimental part}

The radiation geometry and dosimetric methods were performed taking into consideration approved procedures and specialized documents in the radiation field [3-6].

Personal dosimeters are Agfa personal monitoring film with FD-III-B type badge and $\mathrm{LiF}(\mathrm{Mg}, \mathrm{Cu}, \mathrm{P})$, GR200A type detector with DIT-MF badge. The Agfa film contains in the more sensible D10 film and less sensible D2 film. Both polystyrene badges are made of SC Nuclear \& Vacuum, Romania and contain different metallic filters.

The irradiation procedure was performed at the secondary standard laboratory for radiation metrology, testing and dosimetry from Horia Hulubei, National Institute for R\&D in Physics and Nuclear Engineering, IFIN-HH. The ${ }^{241} \mathrm{Am}$ standard source activity was $6.5 \mathrm{GBq}$ with the dose rate at $50 \mathrm{~cm}$ distance of $174 \mu \mathrm{Sv} / \mathrm{h}$ without phantom and $187 \mu \mathrm{Sv} / \mathrm{h}$ on phantom.

The TLD and film dosimeters were placed on the PMMA phantom within the radiation solid angle of the ${ }^{241} \mathrm{Am}$ standard source. Three or six film dosimeters and three TLDs were irradiated to each notable dose from $0.01 \div 10.0 \mathrm{mSv}$ range. Only for following doses: $1.00 \mathrm{mSv} ; 5.00 \mathrm{mSv} ; 7.50 \mathrm{mSv}$ and $8.73 \mathrm{mSv}$ each six film dosimeters were used. The detector responses were used for the $\mathrm{Hp}(10)$ dose equivalent measurement.

\section{Results and discussions}

The film detector has $3 \times 4 \mathrm{~cm}^{2}$ area that means $12 \times 3 \mathrm{~cm}^{2}$ or $12 \times 6 \mathrm{~cm}^{2}$ monitored area. The TL dosimeter contain 5 chip detectors sprayed into the dosimetric badge of $3.5 \times 6 \mathrm{~cm}^{2}$. From middle towards outside of the solid angle the dosimeters were arranged in the semicircle as follows: $\mathrm{Au}, \mathrm{Bu}, \mathrm{Cu}$ and $\mathrm{Ad}, \mathrm{Bd}, \mathrm{Cd}$ film dosimeters toward upper left and down left, respectively and Ad', Bd', Cd' TL dosimeters toward right part. The TL dosimeters were placed in line with the $\mathrm{Ad}, \mathrm{Bd}, \mathrm{Cd}$ 
film dosimeters. For very low energy is recommended the dose assessment taking into consideration the film response under plastic filter.

In Table I the optical density mean values measured on the films under plastic filter of the badge are presented. The background optical densities were $0.42 \pm 1.7 \%$ and $0.14 \pm 0.0001 \%$ for D10 and D2 films, respectively. The optical density mean values were calculated on three or six dosimeters exposed to ${ }^{241} \mathrm{Am}$ source in the same time. Referring to the D10 film plastic filter the optical density standard deviation at $1.00 \mathrm{mSv}$ is over $11 \%$.

The optical density measured on the less sensitive D2 film are more uniform on the studied area.
The maximum of standard deviation is $<7 \%$ in point of $8.73 \mathrm{mSv}$ dose under plastic filter. The optical density deviation on the D2 film under same filter and at low doses is hardly to measure. Also, the first response was obtained over $0.50 \mathrm{mSv}$ under plastic filter and over $5.00 \mathrm{mSv}$ under $\mathrm{Pb}$ filter.

Although the optical density difference from one dosimeter to another are not significant in case of dose calculation high differences are possible to exist. In Table II the doses were calculate using the ${ }^{241} \mathrm{Am}$ calibrate curves fitted by mathematical equations which the best approximates the film dosimeter response.

Optical densities measured on D10 and D2 films under plastic filter.

TABLE I

\begin{tabular}{c|c|c|c|c|c|c|c|c}
\hline \hline & $\mathrm{Hp}(10)_{\mathrm{cv}}$ & 0.01 & 0.05 & 0.10 & 0.50 & 1.00 & 2.00 & 5.00 \\
$\mathrm{D} 10$ & plastic & 0.51 & 0.76 & 1.08 & 2.88 & 4.41 & 5.67 & 6.27 \\
& $\mathrm{SD}$ & 0.02 & 0.01 & 0.03 & 0.11 & 0.52 & 0.06 & 0.08 \\
\hline \multirow{3}{*}{$\mathrm{D} 2$} & $\mathrm{Hp}(10)_{\mathrm{cv}}$ & 0.50 & 1.00 & 2.00 & 5.00 & 7.00 & 8.73 & 10.00 \\
& plastic & 0.18 & 0.21 & 0.29 & 0.51 & 0.66 & 0.77 & 0.94 \\
& $\mathrm{SD}$ & 0.01 & 0.01 & 0.001 & 0.02 & 0.04 & 0.05 & 0.01 \\
\hline
\end{tabular}

Note: $\mathrm{Hp}(10)_{\mathrm{cv}}$ - dose equivalent conventional true value; SD - standard deviation.

Calculated dose distribution in the studied area and recorded with film dosimeter.

TABLE II

\begin{tabular}{c|c|c|c|c|c|c|c|c|c|c|c}
\hline \hline \multirow{2}{*}{$\begin{array}{c}\text { Dose } \\
\mathrm{Hp}(10)_{\mathrm{cv}}[\mathrm{mSv}]\end{array}$} & \multicolumn{3}{|c|}{$\mathrm{Hp}(10)[\mathrm{mSv}], \mathrm{D} 10$ film, plastic filter } & \multicolumn{4}{|c}{$\mathrm{Hp}(10) \mathrm{mSv}, \mathrm{D} 2$ film, plastic filter } \\
\cline { 2 - 11 } $\mathrm{Ad}$ & 0.05 & 0.10 & 0.50 & 1.00 & 0.5 & 1 & 2.00 & 5.0 & 7.50 & 8.73 & 10.00 \\
$\mathrm{Bd}$ & 0.05 & 0.10 & 0.48 & 1.07 & 0.62 & 0.99 & 1.99 & 4.85 & 7.21 & 8.58 & 10.20 \\
$\mathrm{Cd}$ & 0.05 & 0.10 & 0.44 & 0.72 & 0.62 & 0.99 & 1.99 & 5.10 & 7.09 & 8.71 & 9.95 \\
$\mathrm{Au}$ & -0.05 & 0.10 & 0.46 & 0.79 & 0.49 & 0.99 & 1.99 & 4.85 & 6.71 & 8.33 & 10.07 \\
$\mathrm{Bu}$ & - & - & - & 0.85 & - & 0.87 & - & 4.60 & 6.47 & 7.34 & - \\
$\mathrm{Cu}$ & - & - & - & 0.70 & - & 0.87 & - & 4.35 & 6.22 & 7.46 & - \\
\hline
\end{tabular}

Note: The calculated mean dose standard deviations on each film dosimeter were under $2 \%$.

The residuum fitting curves were $5.8 \%$ and $2.3 \%$ for D10 and D2 film, respectively.

Calculated dose distribution in the studied area and recorded

TABLE III with termoluminescent dosimeters.

\begin{tabular}{c|c|c|c|c|c|c|c|c|c}
\hline \multicolumn{2}{c|}{ Dose $\mathrm{Hp}(10)_{\mathrm{cv}}[\mathrm{mSv}]$} & 0.01 & 0.05 & 0.50 & 0.10 & 1.00 & 2.00 & 5.00 & 7.50 \\
\hline \multirow{2}{*}{ Dose $\mathrm{Hp}(10)$} & Ad' & 0.01 & 0.05 & 0.49 & 0.09 & 0.97 & 1.80 & 5.00 & 6.11 \\
calculated & Bd' & 0.01 & 0.05 & 0.49 & 0.10 & 0.89 & 1.86 & 4.47 & 6.58 \\
& Cd' & 0.01 & 0.05 & 0.46 & 0.09 & 1.06 & 1.84 & 4.31 & 6.03
\end{tabular}

The dose of $0.01 \mathrm{mSv}$ is hardly to be assessed although the D10 film records image. The optical density difference from one to another metallic filter shape cannot be measured by the densitometer equipment. The doses under $1.00 \mathrm{mSv}$ and those beginning $1.00 \mathrm{mSv}$ can be assess on D10 film and D2 film, respectively. The doses recorded by $\mathrm{Au}, \mathrm{Bu}, \mathrm{Cu}$ deviate more from conventional values than those recorded by $\mathrm{Ad}, \mathrm{Bd}, \mathrm{Cd}$. The calculated doses by thermoluminescent method are very closed to the conventional true value especially in the very low dose range, as it can see in Table III.

The calculated mean dose standard deviations on each TLD were under $2 \%$. Some difference appears to the third or fourth decimals. At higher doses the 
measurement errors increase. Thus, for the $7.5 \mathrm{mSv}$ conventional dose the error is even $20 \%$. After $5.00 \mathrm{mSv}$ the reading TL method have to be changed [5].

\section{Conclusion}

The dose distribution in the radiation solid angle of a ${ }^{241} \mathrm{Am}$ standard source was studied taking into consideration that some differences of the dose rate in some places from studied area are possible. Although, all the detectors were placed in the solid angle the film dosimeters placed in the upper of the studied area record lower doses. This aspect it is important to the dosimeter response calibration to drawing sensitometric curves. And also, the all body dose assessment for personal occupational exposure is influenced by the dose distribution.

\section{Acknowledgments}

The financial support for this work was sustained by the Nucleu Project, PN 16420203.

\section{References}

[1] National Commission for Nuclear Activities Control, Fundamental Norms for Radiological Safety, Published in the Official Law Bulletin, part I, no. 404, Bucharest 2000.
[2] National Commission for Nuclear Activities Control, Norms on Individual Dosimetry, Published in the Official Law Bulletin, Part I, no. 769, Bucharest 2002.

[3] ISO 4037-1:2019, $X$ and gamma reference radiation for calibrating dosemeters and dose rate meters and for determining their response as a function of photon energy - Part 1: Radiation characteristics and production methods, International Organization for Standardization 2019

[4] ISO 4037-3:2019, $X$ and gamma reference radiation for calibrating dosemeters and dose rate meters and for determining their response as a function of photon energy - Part 3: Calibration of area and personal dosemeters and the measurement of their response as a function of energy and angle of incidence, International Organization for Standardization 2019.

[5] G. Portal, W.G. Cross, G. Dietze, J.R. Harvey, R.B. Schwartz, Measurement of dose equivalent from external photon and electron radiations, ICRU Report 47, International Commission on Radiological Protection, Bethesda 2016.

[6] CEI/IEC 61066:2006-06, Thermoluminescence dosimetry systems for personal and environmental monitoring, International Electronical Commission, Geneva 2006. 